\title{
Primary discussion and empirical analysis of the comparison between college traditional teaching and flipped classroom
}

\author{
Qiaoqin Tan \\ Educational Information Technology Center, China West Normal University, Nanchong, 637009, China
}

Keywords: College traditional teaching, Flipped classroom, Comparison, Empirical analysis.

\begin{abstract}
There exist a lot of problems and defects in college traditional teaching which seriously influence students' learning efficiency and effect. With the execution of new curriculum reform, flipped classroom is widely used in colleges and well received among teachers and parents. Compared with traditional teaching, flipped classroom has obvious advantages. This paper has analyzed problems existing in college classroom teaching and the advantages of flipped classroom with college traditional education and flipped classroom as discussion object, and then made empirical analysis on the comparison between college traditional teaching and flipped classroom, and finally obtained problems existing in its implementation and improvement countermeasures and suggestions.
\end{abstract}

\section{Introduction}

Flipped classroom was initiated and carried out earliest in America as it had significant application effect and greatly improved students' learning efficiency and teaching effect. So it is very popular in US. With economic development in China and globalization tide, flipped classroom spread to China and attracted educators' attention in line with the requirement of new curriculum reform. At present, a lot of domestic researchers have taken detailed research on the concept and application scope of flipped classroom teaching mode but limited to itself. Few have made comparison with traditional teaching. To help people to obtain in-depth knowledge and understanding of flipped classroom, the author has comprehensively elaborated the correlation and difference between traditional teaching and flipped classroom, and then made empirical analysis on the comparison in the hop of promoting and implementing flipped classroom in different colleges and universities in China.

\section{Problems existing in China's college classroom teaching}

So far more and more universities have pay huge attention to school ranking and evaluation so that there exist serious imbalance between scientific research and teaching. With the expanding enrollment, the current teaching situation is getting more and more serious. The whole society has attached great importance to this. WE can find from relevant survey research that phenomena that students play mobile phone, sleep and play games, or even leave early with no reason, cut school and replace other students, etc. exist in most Chinese colleges. There is hardly interaction between teachers and students. Learning atmosphere is bad. These problems are directly related to teachers' application of traditional teaching modes such as cramming teaching method and "teacher-centered" method. Students' subject position is ignored and they lack independent thinking and chances to communicate with teachers and classmates. These have led to students' low learning activity, harmful for improving learning quality. 


\section{Advantages of implementing flipped classroom in colleges}

\section{Pay attention to cultivate students' self-learning ability}

Flipped classroom requires students to automatically preview the knowledge points before formal class so as to prepare and learn the part for memorizing and reciting. At class, teachers are responsible for helping students to find out problems and guide them to explore problems for solution. Then teachers should help internalize and evaluate the knowledge points and organize teams for discussion and mutual exchange to learn lessons and other ideas so as to help students understand knowledge points and connect knowledge with life realities to form a systematic learning system. The whole process with students as the subject respects students' ideas and suggestions and consciously cultivates students' self-learning ability so as to improve learning quality and efficiency.

\section{Promote and implementing individualized teaching}

Traditional teaching environment is usually a large class gathering 50 to 60 students. Teachers cannot question or focus each one of them as time for classroom teaching is limited and teachers have limited energy so as not to consider each student's learning level and schedule. In this case, it will be hard to improve students' score. But flipped classroom provides online study and evaluation which can help teachers evaluate their daily learning effect. Teachers can also know students' learning condition and progress through evaluation so that subsequent teachers can take different teaching strategies based on students' actual condition. This can guarantee the smooth implementation of individualized teaching and promote the introduction and execution of individualized teaching concept.

\section{Adapt to current educational reform trend}

With rapid development and progress of information science technology, knowledge will update faster and faster which makes college teaching mode timely reform and give up traditional teaching mode and concept. Flipped classroom's features accord with current educational development trend. Multiple micro-course video and interesting e-course can combine digital technology with modern education perfectly to satisfy students' demand of online learning. In addition, flipped classroom pays attention to cultivate students' innovation awareness and self-learning ability to compensate the absence of talents in the society. In other words, talents cultivated by flipped classroom are required in social development.

\section{Empirical analysis on the comparison between college traditional teaching and flipped classroom}

\section{Difference of educational concept}

Traditional teaching mode is teacher centered. Even a lot of educational scholars are actively advocating students' dominant role and calling for student-centered new teaching mode, the fact is that many college teachers think they are not able to apply "student centered" education model which advocated by modern educational theory and they feel hard to continue. So "teacher centered" classroom teaching model is still the dominant model under which teachers become performers and students are audience, which put the cart before the horse. The classroom atmosphere is rigid with no communication between students and teachers.

But in flipped classroom, it is fundamentally different with traditional teaching concept in the teaching concept from teacher centered to student centered. So teachers are no longer the dominator in class but pay more attention to students' interest and learning level and basis with individualized teaching concept throughout the whole class. This has increased interaction between teachers and students and enriched classroom atmosphere, improved students' learning interest. In a word, all activities in classroom education is conducted with students centered. 


\section{Difference of teaching content}

Classroom teaching contents under traditional teaching mode is basically determined by the teaching content which is single and inflexible and backward. Teachers are responsible for instructing knowledge points in teaching materials to students. Due to time limit, teachers' instruction content is just in the teaching material with no relation to real life to expand students' knowledge scope. So traditional teaching contents are all completed by teachers.

The emerging of flipped classroom provides students chances to learn new knowledge beyond teaching materials and teachers will arrange knowledge before class for students' preview and guide them to find, analyze and solve problems in formal class. So teachers will give more time for students to think and discuss and train their self-learning ability. In addition, flipped classroom focuses on knowledge expansion and relation to real life, cultivates students' ability to apply textbook knowledge to real life so as to expand their vision and thinking to realize real application.

\section{Difference of teaching organization}

Traditional teaching organization has a great feature of instructing which means teachers are responsible for instructing during the whole process but students just listen with no time and chance to think. They learn and receive knowledge passively. In addition, teachers will put all knowledge to PPT or exercises from the beginning to the end so that students have no time to digest or communicate with teachers.

But flipped classroom teaching can combine listening and asking. Listening means that teachers should listen and observe students' learning condition and progress so as to find out their problems. Asking means that teachers should ask or communicate with students directly and guide them to find out problems, cultivate students' ability to discuss and analyze problems so as to solve problems finally. This teaching mode can stimulate students' creative thinking and innovative awareness.

\section{Difference of learning drive}

The reason why traditional teaching mode cannot achieve good teaching effect is directly related to students' drive as it purely emphasizes score and performance but students cannot be driven so that they cut school and leave early with no reason. Students think it is enough if they can pass the final exam. They just study passively so as not to improve their learning efficiency.

But in flipped classroom, teachers pay more attention to cultivating students' learning interest as it is the best teacher. Students will have more learning power and learn automatically out of interest without supervision. In flipped classroom teaching mode, teachers will leave most time to students and guide them to design teaching steps, communicate with each other. In this case, students can cultivate their learning interest and improve their activity and learning efficiency greatly.

\section{Problems and suggestions of implementing flipped classroom}

\section{Reasonably set teaching load}

During the process of specially implementing flipped classroom, teachers' work load will be increased as teachers must prepare for micro-videos or ppt in advance up to certain requirements, i.e. to be vivid with strong on-spot sense, along with teachers' oral interpretation, to present funny and vivid class atmosphere for students. In this case, teachers' work load will increase greatly. It may take them several hours to make videos. In addition, considering the current situation in China, most colleges emphasizes the publication of achievements in scientific research and professional titles, so that they do not pay much attention to teaching. In the overall environment, teachers should be devoted to flipped classroom with a reasonable setting of teaching work. In addition, colleges can regard the teaching effect of flipped classroom implementation as one of factors for professional title evaluation. In this case, with a system guarantee, flipped classroom can be promoted smoothly. 


\section{Scientifically control teaching cost}

Flipped classroom is implemented by virtue of streaming media teaching video. Students and teachers communicate with network tools or exchange online, which has raised requirements for college network environment and the study condition. So how to scientifically control teaching cost has become a difficulty to implement flipped classroom.

The author thinks that as almost every college student has smart phone which is equipped with PC and usb flash dick function, so it is practical for students which are not well-off. Regarding network environment, online communication and Q\&A between students and teachers, the public network platform QQ group can be used effectively which has strong interactive software and comment function to guarantee the smooth interaction between teachers and students.

\section{Cooperate with teaching resource effectively}

At present a lot of colleges have energetically introduced doctoral students with advanced degree for the purpose of evaluation and ranking so as to increase school scientific research ability. They have high academic qualifications, but they don't have abundant teaching experience and scientific teaching methods, without clear understanding of the implementation process of classroom teaching so that they are hard to control the whole class. Meanwhile, some senior teachers depending on blackboard, chalks and teaching materials are not good at information science technology and not able to use online education model. Based on above cases, the author thins that the best method is to combine both. Experienced senior teachers can guide young teachers to prepare class, organize teaching and deal with emergencies at class. Senior teachers can also learn how to make ppt and teaching videos including how to proficiently use internet tools for teaching. In this way, under the mutual support of both, they can complement each other's advantages and mine out the best potential resources.

\section{Conclusion}

To sum up, based on empirical analysis of comparing traditional teaching and flipped classroom, the author has led us to take an in-depth understanding of problems existing in traditional teaching and advantages of flipped classroom for the purpose of promoting flipped classroom more successfully. On this basis, the author has proposed some suggestions to strengthen the effect of flipped classroom teaching so that more teachers and students can recognize flipped classroom in the hope of improving current education situation and teaching quality to a certain degree.

\section{Acknowledgements}

School-level Talent Project Support: "Studies on the interaction of college flipped classroom and its influence mechanism on teaching effect", Project No.: 17yc191.

\section{References}

[1] Ye Qing, Li Ming. Empirical analysis on comparing college traditional teaching and flipped classroom, Modern Educational Technology, 2015-01-15.

[2] Zhang Shanming, Liu Shugang. Comparison of the teaching effect of traditional classroom and flipped classroom---take mental health education as the example, Forum on Contemporary Education, 2016-10-08.

[3] Zhang Zhu, Han Tian. Challenges and opportunities for college traditional education under Mooc era, Deepen educational reform and improve higher education quality (volume 1), 2015-12-19.

[4] Liu Xiang, Qi Haijing. Studies on information retrieval flipped classroom teaching model and supporting platform, Library and Information Service, 2016-11-20. 
[5] Chen Xiaolu, Wu Helan, Wang Zuyuan, comparative study on MOOC classroom and traditional classroom teaching effect---take physics course in Tongji University as the example, China Edu Info, 2016-02-10. 